\title{
Futuring European industry: assessing the ManuFuture road towards EU re-industrialization
}

\author{
Björn Sautter ${ }^{1}$
}

Received: 15 August 2016 / Accepted: 19 November 2016 / Published online: 9 December 2016

(C) The Author(s) 2016. This article is published with open access at Springerlink.com

\begin{abstract}
Industry is the backbone of the European economy - producing $80 \%$ of Europe's exports, accounting for $80 \%$ of private Research, Technology Development and Innovation (RTDI) expenditures, and providing more than 30 million jobs with additional 70 million in related sectors. Thus, the manufacturing sector plays a vital role in fostering economic growth and social welfare across Europe, and it has the potential to provide innovative solutions for the grand societal challenges. However, European Industry's share of added value has substantially decreased during the last decades. Against this backdrop, the European ManuFuture platform was created in 2003 to provide visions, scenarios as well as RTDI strategies and roadmaps for the re-industrialization of Europe. This article recapitulates the successful Vision 2020 generation and implementation process of the ManuFuture community. Based on a systemic assessment of the multi-actor, multi-governance-level and multi-sector policy approach, success factors are elaborated as guiding principles and framework for the upcoming Vision 2030 process. With reference to currently discussed issues in the European Research and Innovation area such as digitising industry and circular economy, this article concludes with some options to pursue the "ManuFuture Road".
\end{abstract}

Keywords Manufacturing industry · Strategic intelligence · Strategic alignment and decision-making · Vision and constituency building $\cdot$ Innovation ecosystem $\cdot$ Knowledge triangle

Björn Sautter

bjoern.sautter@festo.com

1 Festo AG \& Co. KG, Ruiter Strasse 82, 73734 Esslingen, Germany

\section{Introduction}

Economic actors have to find their way in an increasingly complex and ever more rapidly changing world of value creation and globally interrelated Research, Technology Development and Innovation (RTDI) activities. For succeeding in the 'competition for the future' [18], it is crucial for them to have a clear idea of upcoming developments and a group of trusted companions on their way into the future. Thus, sustainable economic success strongly relies on effectively gathering strategic intelligence (SI) as well as on strategic decision-making on and alignment of future-oriented RTDI investments and activities at multiple levels, from business to networks to political governance level [30].

Against this backdrop, 'futuring' activities can help 'future-proofed' decision-making and guiding communities and organisations to jointly realise common visions of the future. Taking into account specific quality criteria, which have been developed for Futures Research and mapping activities [25, 26], helps unleashing the full potential of such activities and increasing the impact within the socio-technologicaleconomic-political environment. Following a systemic and integrative approach - combining forward- and outwardlooking as well as action-planning and action-taking activities along the strategy/policy cycle [6] — substantially contributes to common vision-building and goal-setting, and thus to strategic alignment of RTDI investments and activities in 'sociotechnical constituencies' [28]. According to Molina, the integration of technical constituents (processes, machines, software etc.) and social constituents (innovation actors with their specific visions, values, etc.) is the fundamental premise for all technological processes and innovation dynamics.

\footnotetext{
${ }^{1}$ Cornish [7] introduced 'futuring' as the art and science of exploring the future
} 
Thus, constituency building can be seen at the core of new ways of value creation in the multi-actor, multi-sector, multilevel innovation ecosystems of the $21^{\text {st }}$ century [4].

Future-oriented decision-making and constituency building is highly relevant for all economic actors and in particular, of great importance in economic sectors with major impact on jobs and growth such as the industry sector for Europe. Industry is the backbone of the European economy, producing $80 \%$ of Europe's exports, accounting for $80 \%$ of private RTDI expenditures, and providing more than 30 million jobs with additional 70 million in related sectors. Thus, the manufacturing sector plays a pivotal role in fostering economic growth and social welfare across Europe, and it has the potential to provide innovative solutions for the grand societal challenges. But - enforced by the financial and economic crisis European Industry's share of added value has decreased tremendously during the last two decades. Against this backdrop, the European ManuFuture platform - a community of researchers, industrialists and public-private-partnership organizations - provides visions, scenarios as well as RTDI strategies and roadmaps for the re-industrialization of Europe [38].

The aim of this article is to assess the ManuFuture Road towards high-adding-value, knowledge-based competitive sustainable manufacturing in 2020 [23] on the basis of quality criteria for Futures Research in order to draw conclusions for systemic 'futuring' activities in general and for the next ManuFuture strategy cycle in particular. The following section explains the need for systemic 'futuring' activities in a complex, knowledge-driven environment and introduces specific quality criteria, as they are currently discussed for Future Research and Foresight processes in scientific publications. In section 3, the ManuFuture background is introduced before the ManuFuture Road 2020 is assessed based on the aforementioned quality criteria. In the final section, conclusions are drawn for systemic 'futuring' activities in general and for the next ManuFuture strategy cycle in particular. In this regard, some references are made to new paradigms such as Digitising Industry, Circular and Sharing Economy, Open Innovation 2.0 and others, which set the frame for the next ManuFuture Road 2030.

\section{Need for futuring in a complex, knowledge-driven environment}

\section{Strategic decision-making and constituency building in a complex environment}

The economic environment for doing business and for sustaining business success in a rapidly changing and globalising knowledge economy is getting more and more complex. Company boundaries are blurring and traditional value chains are breaking up, when - enabled and accelerated by advanced ICT solutions - new modes of networked knowledge generation and application emerge and the paradigm of open and collaborative innovation is becoming more and more widespread $[14,29]$. In this new world of open and collaborative innovation, multiple actors from various domains interact with each other across multiple levels, organised in a selfreferential and 'fractal' knowledge ${ }^{2}$ and innovation architecture.

To develop innovative solutions - in particular for tackling the grand societal challenges of the 21 century, and thus for succeeding in future global markets-actors from industry have to interact and strategically align their RTDI investments with actors from academia and government (Fig. 1). Industry actors rely on cutting-edge technological knowledge, which is mostly generated in globally networked science communities and on public co-investments, e.g. in education and research infrastructure in order to reduce the risks for longer-term investments in complex RTDI processes with their inherent uncertainty. The reciprocal relations between the 'triple helix' actors from university, industry and government build the core of each innovation ecosystem [10]. The innovation actors are embedded in a media- and culture-based system, including the broader public and civil society, as well as in the natural environment of society and economy. The natural environment provides on the one hand important resources for economic activities and poses on the other hand grand challenges to global society, which are a key driver of innovation in a 'quintuple helix' innovation ecosystem [5].

In the context of the shifting innovation paradigm from 'closed' to 'open' innovation thinking at the micro level, a more open and systemic understanding of innovation governance emerged at the policy level, too [33]. Striving for better societal impact of public and private RTDI investments, policy-makers increasingly promote public-private partnerships and provide with the grand societal challenges incentives for broad and strategically aligned public and private investments, as priority fields in "new" RTDI programmes and strategies at multiple governance levels (Table 1). Thus, referring to the open innovation approach, an 'open method of coordination' has been adopted for orchestrated investment strategies in the European Research Area (ERA).

Against this backdrop, strategic intelligence $(\mathrm{SI})^{3}$ is needed at multiple levels to strategically align RTDI-related investment decisions in the broad innovation landscape. Strategic alignment primarily means mutually communicating and translating visions of future developments and strategic targets between 'triple-helix' innovation actors in order to provide each stakeholder with the appropriate 'frame' for the strategic

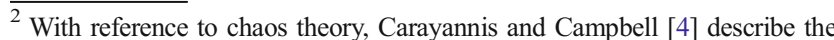
complex and knowledge-driven environment as " 21 st century fractal research, education and innovation ecosystem".

${ }^{3}$ Tübke et al. [34] defined strategic (policy) intelligence as "the set of actions to search, process, diffuse and protect information to make it available to the right person at the right time in order to make the right decisions"
} 
(knowledge society and knowledge

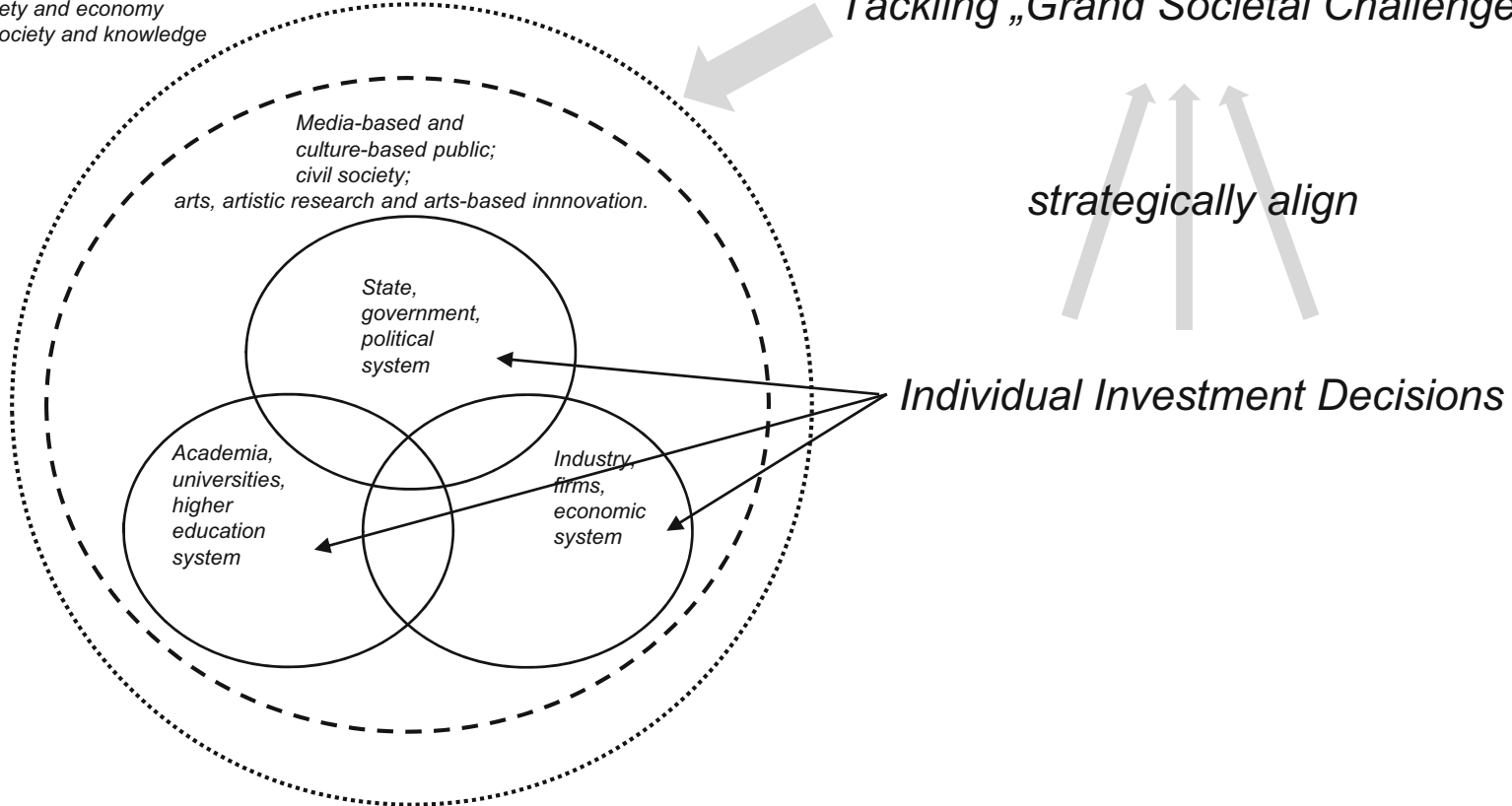

economy)

Tackling „Grand Societal Challenges“

Fig. 1 Strategic alignment of investments in a 'quintuple helix' innovation system (Source: extended illustration based on [3])

decisions-making in his specific context [35]. In the following it will be explained, how 'futuring' activities can support strategic decision-making and constituency building for collective actions and orchestrated RTDI investments in a complex and knowledge-driven environment.

\section{Futuring to support strategic decision-making and constituency building}

Edward Cornish - former president of the World Future Society and editor of the magazine The Futurist - described
2004 in his book entitled 'Futuring: The Exploration of the Future' with the term 'futuring' a pragmatic approach to "understand possible future developments, make better decisions, develop worthwhile goals, and find the means to achieve them" [7]. According to Cornish, 'futuring' can help "guide communities and organisations to a successful future" in the sense of guiding synchronised actions on a common road towards an aspired vision of the future, which is broadly shared in the community. Thus, 'futuring' activities can contribute not only to strategic decision-making but also to constituency building, if the respective social constituents

Table 1 Multiple governance levels with RTDI programmes and strategies in the European Research Area (source: [30])

Governance level

European level

Trans-regional/trans-national level of publicprivate partnerships

National level, e.g. Germany

Regional level, e.g. Baden-Württemberg
Examples for RTDI policies, programmes and related strategies

Europe 2020 strategy and its flagship initiative "Innovation Union"

Horizon 2020 - The EU Framework Programme for R\&I

Cohesion Policy 2014-2020 with R\&I Strategies for Smart Specialisation (RIS3)

Strategic R\&I Agendas / Roadmaps or Strategic Implementation Plans of

- European Technology Platforms (ETPs)

- Joint Technology Initiatives (JTIs)

- Contractual Public Private Partnerships (cPPPs) in research

- Knowledge \& Innovation Communities (KICs) of the European Institute for Innovation and Technology (EIT)

- European Innovation Partnerships (EIPs)

National High-Tech Strategy 2020

National Excellence Initiative

National Strategy for Internationalisation of Science and Research

National Strategy on the European Research Area (ERA)

Innovation Strategy Baden-Württemberg

R\&I Strategies for Smart Specialisation (RIS3) at regional level and for 'functional areas' 
(innovation actors with their specific visions, values, etc.) are involved right from the beginning. In this regard, 'futuring' activities follow a participatory, systemic and integrative approach, combining SI tools such as Foresight, impact assessment, roadmapping etc. along the policy cycle (Fig. 2) with:

- Outward-looking activities to identify appropriate innovation actors as well as stakeholders influencing the relevant framework conditions in the broader innovation ecosystem;

- Forward-looking activities to identify emerging needs and to develop joint visions and attractive common goals motivating all relevant stakeholders to join their forces and following aligned longer-term investment strategies;

- Priority-setting and action-planning activities, complementing forward- and outward-looking activities at multiple levels, to transform joint visions into strategically aligned actions from micro-level business development to macro-level governance of innovation ecosystems.

Accordingly, 'futuring' helps strategically aligning decision-making of multiple actors from multiple sectors at multiple levels by common vision-building (perceptionalignment) and goal-setting (goal-alignment), and thus contributes to effective constituency building leading to optimised impact of orchestrated RTDI investments.

To ensure an effective process and a broad impact of 'futuring' activities, specific quality criteria are currently discussed in the scientific literature [25]. In the following, some of these quality criteria are outlined from a practical and impact-oriented point of view.

\section{Quality criteria for futuring activities}

Kuusi et al. [25, 26] recently developed quality criteria for Futures Research and futures mapping activities. They use a pragmatic understanding of validity criteria and distinguish internal validity of the process from external validity of the results.

The internal validity of 'futuring activities refers to the sound use of methods and tools and a well-organized, action-oriented process contributing to the 'shaping of the future'. With reference to the European Forum on Forward Looking Activities [13], which recommends for all forwardlooking processes the integration of strategic intelligence and sense-making activities along the policy cycle, Kuusi et. al [25] propose to clearly determine the objective, the scope and type of activity, the appropriate set of methods as well as the intended outcomes of the 'futuring' activity right from the beginning. In accordance with supplemental findings on quality criteria for implementing systemic Foresight activities in practice $[25,31]$, following main quality criteria for internal validity of 'futuring' activities can be summarised from a practical point of view:

- Goal and stakeholder oriented design of the 'futuring' initiative (well-defined scope with focus on the relevant actors and their specific objectives);

- Systemic and participatory approach with broad stakeholder involvement and engagement in the 'futuring' process;

- Integrative approach with appropriate combination of strategic intelligence and sense-making activities and a proper use of SI tools along the policy cycle;

- Action and impact oriented process with focus on implementing the jointly developed "futuring" results.

The external validity of "futuring" activities refers to the results, if they are evidence-based (supported by facts, observations and established theories concerning the relevant causal processes) and in particular, if relevant actors are able to understand and to use the results [25]. The latter criterion directly refers to the impact of the 'futuring' process and results. From
Fig. 2 Strategic intelligence tools along the policy cycle (Source: based on [6])

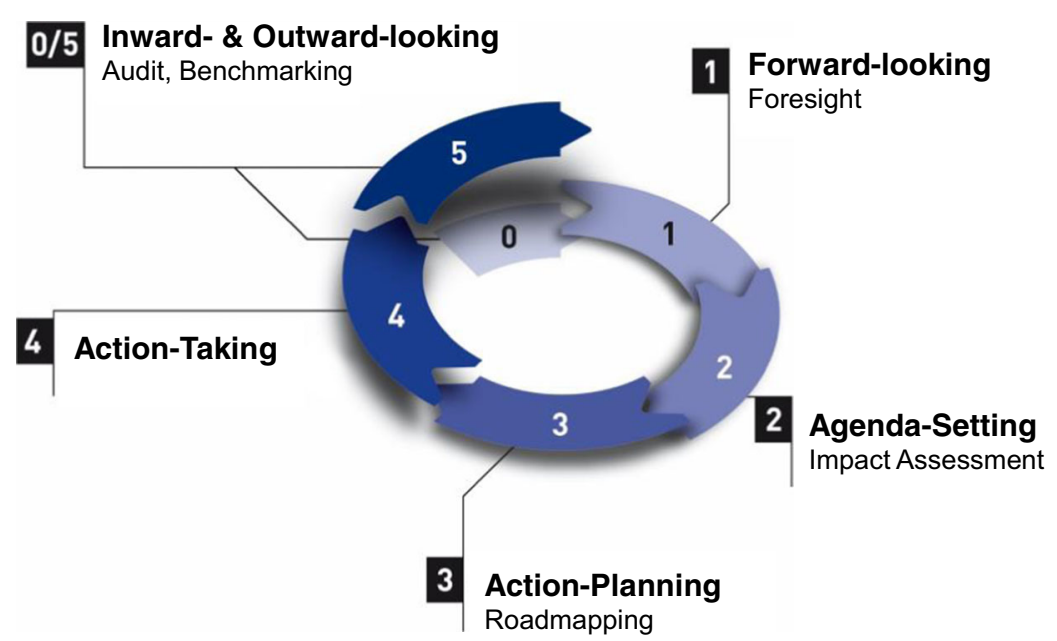


a pragmatic point of view, the impact can be seen as the main criterion for assessing 'futuring' activities, as their primary aim is to shape the future. Thus, from a practical and impact-oriented perspective [1], the more impact a 'futuring' process has achieved in the socio-technological-economicpolitical environment, the more successful it has been. In other words, effective 'futuring' activities substantially contribute to strategic decision-making and constituency building at multiple levels - from macro-level governance of innovation ecosystems, to meso-level value chains and networks, to microlevel innovation actors.

In the following the ManuFuture Vision 2020 generation and implementation will be introduced, before the ManuFuture Road 2020 will be assessed based on the aforementioned quality criteria from a practical and impactoriented point of view.

\section{Assessing the ManuFuture road: vision 2020 generation and implementation}

\section{The ManuFuture road towards competitive and sustainable manufacturing}

At the turn of the third millennium, rising public awareness of upcoming economic, social, environmental and technological challenges of the $21^{\text {st }}$ century brought the issues of sustainability, and in this context, of manufacturing as a key enabler for sustainable development, high on political agendas. The rising political awareness of the relevance of competitive sustainable manufacturing at world level and the tremendously decreasing industry's share of added value in Europe led to various initiatives at EU level. The European Commission promoted and supported a bundle of activities concerned with the future of manufacturing comprising:

- The projects "Future of Manufacturing in Europe 20152020 - The Challenge for Sustainable Development (FuTMan)" and "Manufacturing Visions - Integrating diverse perspectives into Pan-European Foresight (MANVIS)";

- The work of an expert group, followed by the first ManuFuture Conference in 2003, initiating a series of annual ManuFuture Conferences;

- The launch of the European Technology Plattform ManuFuture in 2004 as industry-led initiative to promote strategically aligned RTDI investments of multiple actors in multiple sectors across multiple levels.

Based on first results achieved by the expert group and discussed at the first ManuFuture Conference in 2003, a High Level Group of European executives from research organisations and industry-invited by the European
Commission - developed a shared vision of the way ahead for EU manufacturing in 2004 [11]. This vision-building process has been utilising the results of the FuTMan project (scenarios on future manufacturing patterns and detailed case studies on selected sectors and crosscutting themes; cf. Geyer et al. [16]) and the EUREKA Factory project Informan (comparative analysis of Foresight studies), and has been accompanied by the MANVIS project, which launched a pan-European Delphi survey on manufacturing issues.

The outcome of the vision-building process, the ManuFuture Vision 2020 of "high-adding-value and knowledge-based competitive sustainable manufacturing (CSM)" has been proposed as European response to the key issues challenging manufacturing such as globalisation, climate change, ageing population, public health, poverty and social exclusion, loss of biodiversity, increasing waste volumes, soil loss etc. [21]. In order to promote the paradigm shift from cost-oriented manufacturing to high-adding-value and knowledge-based competitive sustainable manufacturing as well as to contribute to the "European Technological and Industrial Revolution for competitiveness and sustainability of manufacturing" [24], the ManuFuture initiative - officially launched as a European Technology Platform in 2004 developed:

- A circular process of SI generation, diffusion, adoption and use along the policy cycle with specific Foresight, roadmapping, implementation and monitoring phases (Fig. 5):

- A reference model for proactive action, highlighting the relevance of a systemic multi-actor, multi-sector and multi-level approach for optimized impact of the ManuFuture initiative (Fig. 3).

According to both, the circular SI process and the ManuFuture reference model, a Strategic Research Agenda (SRA, with five priority pillars) ${ }^{4}$ has been developed in 2005 , and sectorial as well as trans-sectorial Roadmaps (with more than 300 defined actions, nearly $80 \%$ of them with relevance for all industrial sectors) has been derived in 2006 [37]. From then on, the implementation phase started with the foundation of national and regional ManuFuture platforms and with collective actions funded by national programmes as well as the 7th EU Framework Programme for Research (FP7). During the financial and economic crisis, the contractual Public-Private Partnership for Factories of the Future

\footnotetext{
${ }^{4}$ The SRA defined following priority fields for collective action: (a) new, high- added-value products and services; (b) new business models; (c) new manufacturing engineering; (d) emerging manufacturing science and technologies; (e) transformation of existing RTD and educational infrastructures to support world-class manufacturing, fostering researcher mobility, multidisciplinary and lifelong learning [27].
} 
Fig. 3 ManuFuture reference model for basic activities and pilot actions (Source: [20])

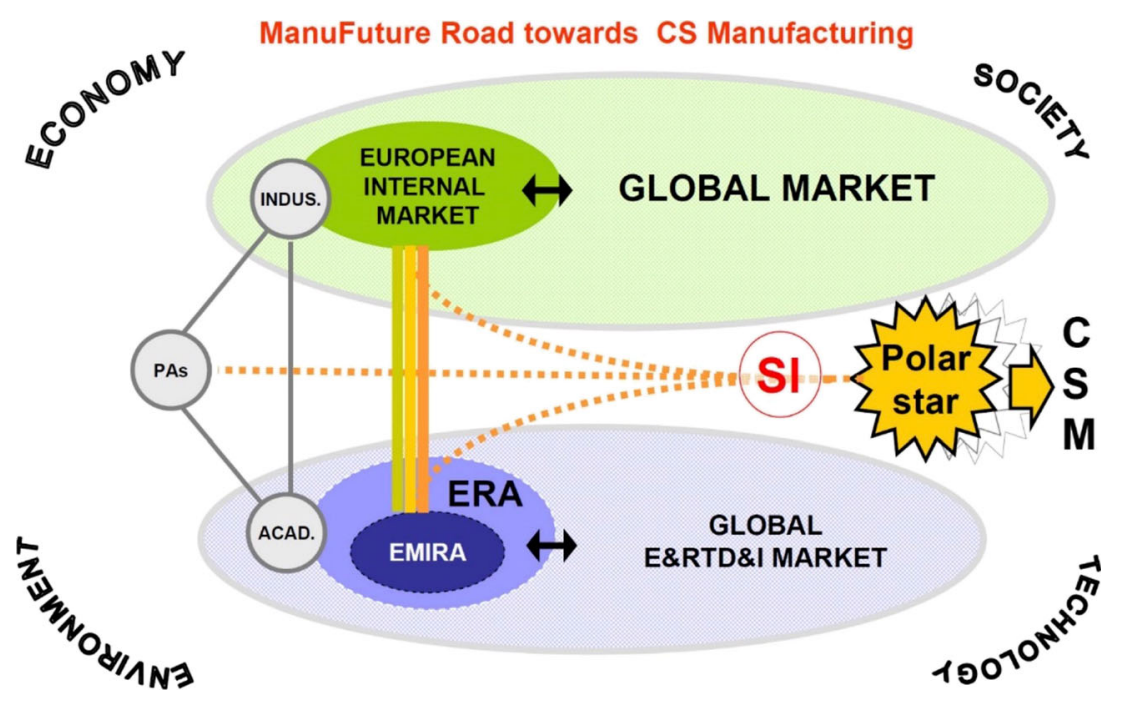

(cPPP FoF) was launched under the European Economic Recovery Plan in 2008 with the aim to enable a more sustainable and more competitive European industry at the centre of Europe's economy - generating growth and securing jobs. To shape, promote and support the implementation of the cPPP FoF - and representing the private side of the PPP - the ManuFuture initiative jointly developed with key industrial associations the industry-driven European Factories of the Future Research Association (EFFRA).

In the following, the ManuFuture Road and in particular the vision and constituency building process as well as the impact on the broad socio-technological-economic-political environment will be assessed by the quality criteria for 'futuring' activities introduced in section 2.

\section{Assessing the ManuFuture vision and constituency building process}

With regard to the quality criteria of goal and stakeholder oriented design, the ManuFuture initiative set from the beginning a clear overall objective, namely to pursue high-adding-value and knowledge-based competitive sustainable manufacturing (CSM), involving the stakeholders from public authorities and financial institutions, to industry, university and research centres. Thus, ManuFuture explicitly followed a 'triple helix' approach to provide the actors from industry, academia and public administration (PA) with strategic intelligence (SI) and a common vision as guiding 'polar star' for their respective RTDI activities and investments (Fig. 3).

The ManuFuture reference model explicitly refers to the actor's domains in which they interact (global markets for industry, global RTDI landscape for academia and framework-setting context for public administration), including the broader economic, societal, technological and environmental context. Accordingly, the ManuFuture initiative aimed at transforming and streamlining activities in all three domains with specific focus on the European Manufacturing Innovation and Research Area (EMIRA) as multi-level domain, where activities along the 'knowledge triangle' education - research - innovation (E\&RTD\&I) are carried out in concerted efforts by all triple helix actors. With the aim to develop the EMIRA as a specific manufacturing-dedicated component of the European Research Area (ERA) - as a basis for sustainable business success on global markets ManuFuture obviously followed a systemic approach of strategic decision-making and constituency-building in a complex environment.

According to the ManuFuture reference model, the ManuFuture process followed a systemic and participatory approach with broad stakeholder involvement and engagement. About 50 high-level executives and experts from research organisations and industry have been involved in the ManuFuture Vision 2020 generation, presenting and discussing the results with a broad audience in the first ManuFuture Conference in 2003. 70+ members of the high-level and support group and of various working groups with representatives from national ManuFuture initiatives and other European Technological Platforms and initiatives have developed the subsequent Strategic Research Agenda (SRA) (ManuFuture, 2006). Within the ManuFuture Vision 2020 and SRA generation process, reference has been made to discussions in the scientific world (e.g. in the International Academy for Production Engineering CIRP [22]) as well as to official policy strategies (e.g. the Lisbon Strategy for Growth and Jobs and the related communication Towards a European Research Area).

A broad stakeholder involvement has been achieved with the online Delphi survey of the MANVIS project, where over 3.000 experts from all-over Europe have been involved [2, 19]. The implementation of the SRA with its five priority fields for collective action consequently followed a multi-level approach (Fig. 4). To involve the largest possible number of stakeholders, national and regional ManuFuture platforms have been 
Fig. 4 Multi-level approach fo European Manufacturing Innovation and Research Area (Source: [20])

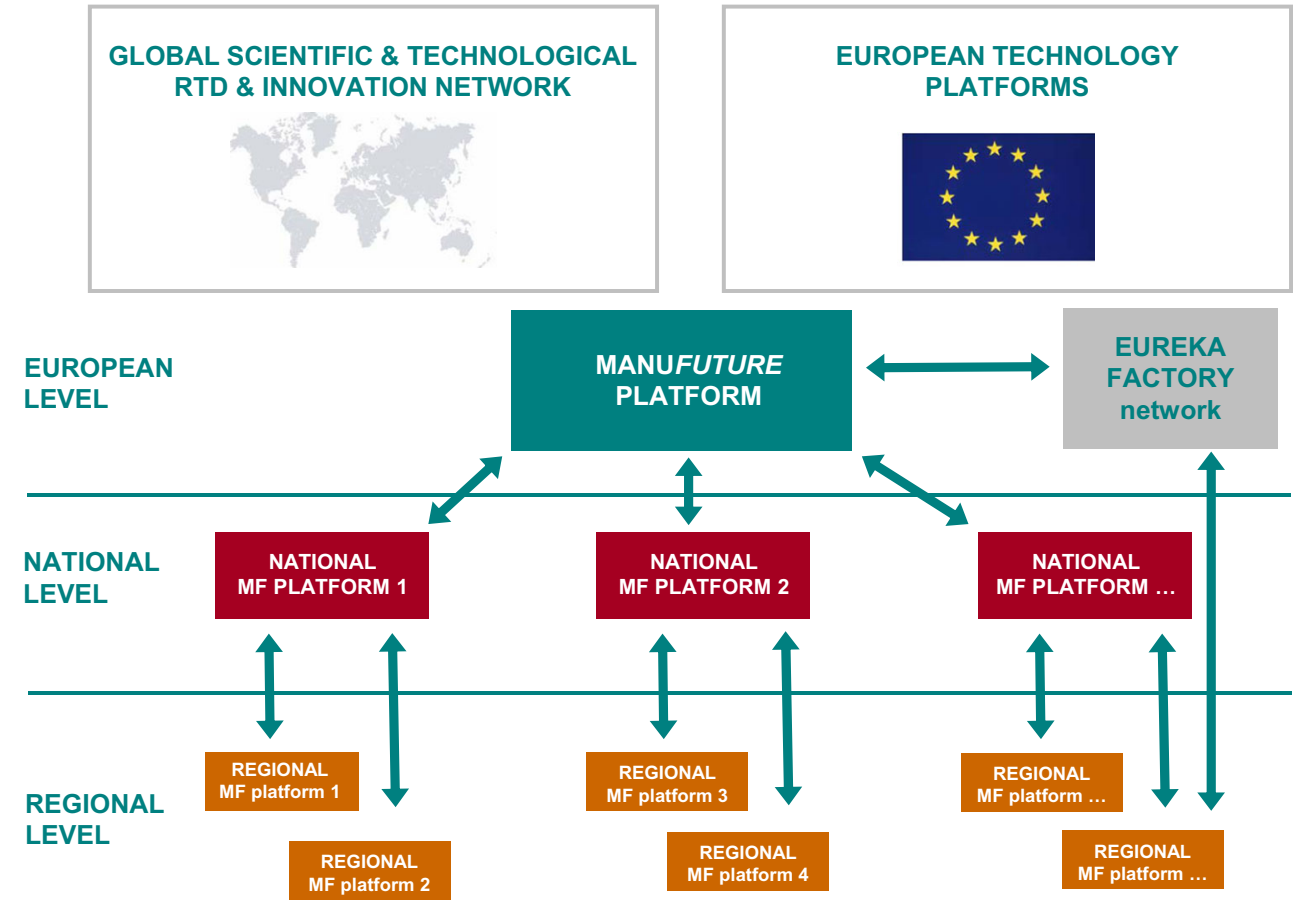

launched in nearly all European member states. These platforms have been mobilising partners, particularly from industry and especially SMEs, facilitating dissemination and demonstration activities, promoting complementary initiatives and attracting private and public funds at national and regional level. With regard to the achieved impact at multiple governance levels as described below (Table 2), the national and regional platforms can be seen as a key success factor for the broad implementation of the ManuFuture Road across Europe. They mobilised national and regional authorities and influenced the creation of national and regional funding programmes, complementary and strategically aligned with the European programmes.
ManuFuture followed an integrative approach with appropriate combination of strategic intelligence and sensemaking activities and a proper use of SI tools along the policy cycle. The developed circular SI process encompasses four complementary activities along the policy cycle (Fig. 5):

- Foresight, enabling well-informed decision making on future investments (mainly related to macro-level policymaking);

- Roadmapping, developing priority areas and fields for collective actions (mainly operating on meso-level and

Table 2 ManuFuture activities and impact on multiple governance levels

Governance level

European level

Trans-regional/trans-national level of public-private partnerships

National level, e.g. Germany

Regional level, e.g. Baden-Württemberg
ManuFuture activities and their impact (a selection)

contractual Public-Private Partnership on Factories of the Future (cPPP FoF) launched under the European Economic Recovery Plan

European Strategy for Key Enabling Technologies (KETs) with advanced manufacturing technologies as one of six defined KETs

European Institute of Innovation and Technology with its goal to launch a Knowledge and Innovation Community (KIC) on added-value manufacturing

European Technology Platform ManuFuture.EU

European Factories of the Future Research Association (EFFRA) providing e.g. strategic multi-annual roadmaps for the $\mathrm{cPPP} F o F$

ERA-NET MANUNET

EUREKA cluster ManuFuture Industry

Vanguard initiative pilot "Efficient \& Sustainable Manufacturing"

National Technology Platform ManuFuture.DE

National Funding for "Research for Tomorrow"s Production" and for "Industry 4.0" a project in the High-Tech Strategy 2020 for Germany

Regional Technology Platform ManuFuture.BW Allianz Industry 4.0 Baden-Württemberg 
Fig. 5 The SI Life Cycle within the ManuFuture Framework (Source: [22])

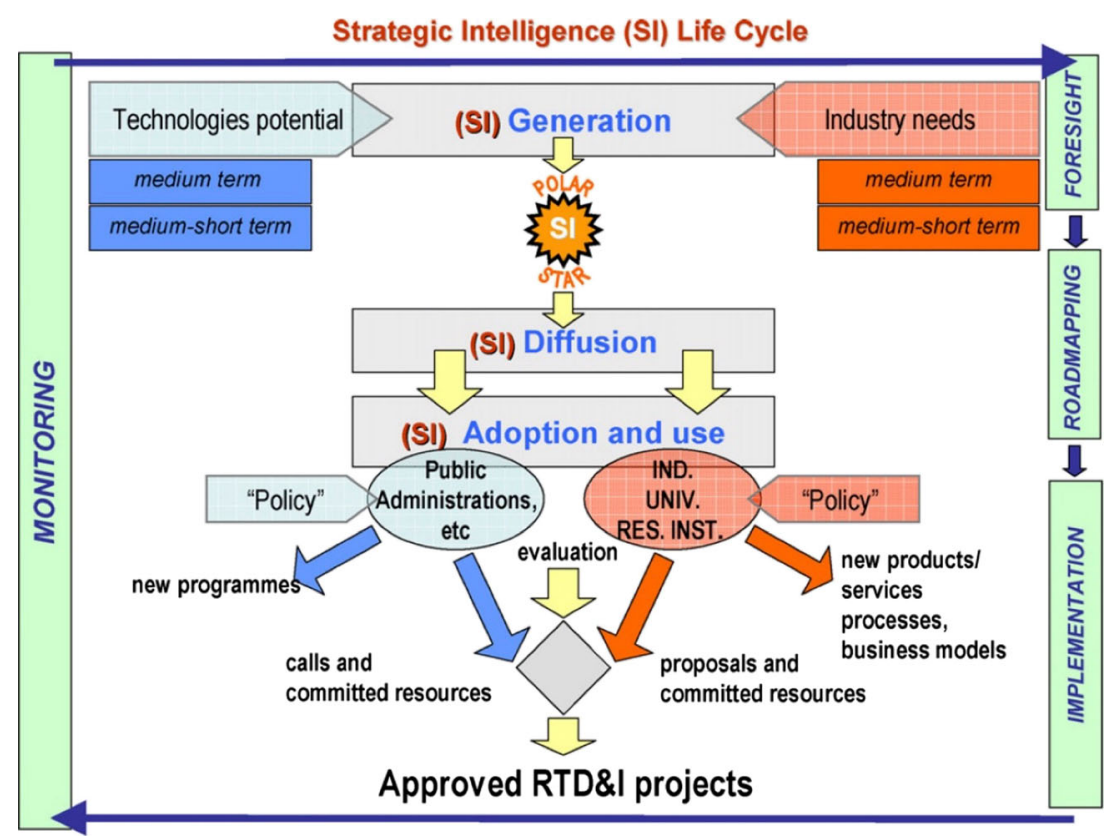

related to new ways of value creation and changing the production and consumption paradigms);

- Implementation with concrete, orchestrated actions of 'triple helix' actors (mainly related to micro-level and related to concrete interventions and actions e.g. for new products/services, processes and business models);

- Monitoring, assessing and evaluating the innovation process towards CSM.

In this context, the generation of SI and its broad diffusion to the largest possible number of stakeholders played an important role in order to facilitate the broad adaption and use of it in concerted efforts along the 'knowledge triangle' education - research - innovation across Europe.

From the outset, the ManuFuture initiative aimed at transforming the European industry and manufacturing-related RTDI system and thus followed an action and impact oriented process with focus on implementing the jointly developed results. The produced documents (Vision 2020, SRA, etc.) have not been produced as an end in itself but as a means to stimulate and strategically align future-oriented RTDI activities and longer-term investments from multiple actors in multiple sectors and across multiple levels. (e.g. supported by the 7th EU Framework Programme for Research as well as national and regional programs). In the following, the ManuFuture impact on the various levels of the socio-technological-economicpolitical environment will be described in more detail.

\section{Assessing the impact} on the socio-technological-economic-political environment

The ManuFuture Road generated impact on all levels, from macro-level governance of innovation ecosystems, to meso- level paradigm shifts in value creation, to micro-level RTDI activities of single actors.

With regard to macro-level governance of the European manufacturing related research and innovation area, ManuFuture achieved impact on multiple governance levels (Table 2). At European level, the contractual Public-Private Partnership for Factories of the Future (cPPP FoF) was launched in 2008 with the aim to enable a more sustainable and more competitive European industry at the centre of Europe's economy - generating growth and securing jobs. The ManuFuture initiative jointly developed with key industrial associations the industry-driven European Factories of the Future Research Association (EFFRA) to represent the private side of the PPP and to shape, promote and support the implementation of the FoF program. Thus, EFFRA developed the multi-annual roadmaps 2010-2013 (for FP7-funded FoF-projects with an indicated overall budget of 1.2 billion EUR) and 2014-2020 (for Horizon 2020 funded projects with an indicated overall budget of 7 billion EUR). According to official EFFRA information, ${ }^{5}$ through this partnership 200+ projects have been already launched with the participation of over 1200 organisations from across Europe.

At national and regional level, about 30 ManuFuture activities have been launched with direct impact on national and regional funding programs. ${ }^{6}$ For example, in Germany, ManuFuture.DE prepared the ground for the upcoming Industry 4.0 platform and ManuFuture. $\mathrm{BW}^{7}$ was funded in 2009 with the aim to launch a national 'leading-edge cluster' as advanced engineering platform for production. The

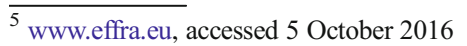

${ }^{6}$ www.manufuture.org, accessed 5 October 2016

${ }^{7}$ www.manufuture-bw.de, accessed 5 October 2016
} 
ManuFuture idea expanded in several European regional research and innovation strategies for smart specialisation (RIS3) leading also to the idea of a trans-regional smart specialization platform for Advanced Manufacturing within the Vanguard Initiative. ${ }^{8}$

At micro-level of innovation actors, the ManuFuture Road influenced strategic investments e.g. in CSM-related products/ services, processes and business models. The ManuFuture vision building and strategy processes inspired companies such as Festo, a leading worldwide supplier of automation technology located with its headquarters in the BadenWürttemberg region, to develop ManuFuture-related RTDI roadmaps. For example, Festo developed market and customer-oriented 'pictures of tomorrow' with tangible goals for Corporate Research and Technology and specific roadmaps that describe the projects on the path to achieve the goals. In line with these roadmaps and in accordance with privately financed projects, Festo invested in publicly cofunded FoF-projects such as EMC2-Factory (clean and competitive factory), ${ }^{9}$ Robust-Planet (shock-robust design of plants and supply chain networks), ${ }^{10}$ LOCOBOT (low cost robot co-workers), ${ }^{11}$ SO SMART (socially sustainable manufacturing for the factories of the future) ${ }^{12}$ as well as in many FoF-related joint projects.

The new RTDI strategies and programs at macro-level and the corresponding actions at micro level stimulated new ways of value creation and paradigm shifts also at the meso level. Beyond the FoF-project consortia with the participation of over 1200 organisations and the aforementioned regional and trans-regional networks and activities, another impact can be seen in the fact that the European Institute of Innovation and Technology ${ }^{13}$ picked up the ManuFuture concept of manufacturing-related knowledge and innovation communities across Europe.. New ways of seamlessly integrating education, research and innovation activities shall be realised in regional 'knowledge triangles' (referring to a new 'learning and teaching factory' paradigm) in order to develop competences and skills needed to promote and support future perspectives of a high-adding-value and knowledge-based competitive and sustainable manufacturing across Europe.

\section{Limitations of the ManuFuture road assessment}

The aim of this paper is to assess the ManuFuture Road from a pragmatic rather than from a philosophical, epistemological point of view [32]. Thus, the preceding assessment of the ManuFuture Vision 2020 generation and implementation

\footnotetext{
${ }^{8}$ www.s3 vanguardinitiative.eu, accessed 5 October 2016

${ }^{9}$ www.emc2-factory.eu, accessed 5 October 2016

${ }^{10}$ www.robustplanet.eu, accessed 5 October 2016

11 www.locobot.eu, accessed 5 October 2016

12 www.chalmers.se/hosted/sosmart-en, accessed 5 October 2016

13 www.eit.europa.eu, accessed 5 October 2016
}

process is based on criteria, that have been derived from pragmatic validity criteria currently discussed in scientific literature [25] and that primarily reflect practical experience with facilitating "futuring" activities 'in the real world' [15, 31]. However, as the ManuFuture Road approach has been rather unique with regard to its comprehensive multi-actor, multi-sector and multi-governance level approach (e.g. ManuFuture platforms at European, national and regional level), no comparative analysis of comparable 'futuring' activities has been included in this paper. Thus, further assessment work is needed to fully apply the comparative analysis of 'futures mapping processes' as suggested by Kuusi et al.[25, 26, 36].

The assessment of the ManuFuture Road is primarily based on information given in publications [22, 23], available documents [11,27] and on websites (e.g. from ManuFuture or EFFRA). Thus, the analysis of internal and external validity criteria mainly relies on the specified description of the ManuFuture approach, reference model, process and results rather than on structured interviews with participants. However, the general findings of this assessment have been approved in personal conversations with several participants of the described process. Some of the involved people confirmed, that the ManuFuture Road has been seen as a 'master' for all experts and people, who has been in charge of RTDI in enterprises, research organisations and governmental institutions in European, national and regional industries. The scientific verification of this statement would have gone beyond the scope of this paper.

\section{Conclusions and implications for ManuFuture vision 2030 generation and implementation}

This article aimed at assessing the ManuFuture Road towards EU Re-Industrialisation based on pragmatic quality criteria for Futures Research in order to draw conclusions for effective 'futuring' activities in general and for the next ManuFuture strategy cycle in particular. The article has described the need for strategic decision-making and constituency building in a complex and knowledge-driven socio-technologicaleconomic-political environment. To meet this need, it has introduced 'futuring' as a pragmatic way to explore future developments in order to make better, "future-proofed", decisions and to strategically guide communities and organisations to jointly realise a common vision of the future [7]. Quality criteria for effective 'futuring' activities have been introduced with specific reference to internal and external validity of the 'futuring' processes and results $[25,26]$. Whereas internal validity refers to well-structured processes, tailored to the stakeholder needs and objectives, and a sound methodological approach, integrating strategic intelligence and sensemaking activities along the policy cycle, external validity mainly refers to the evidence-based results and in particular 
to the impact in the broad socio-technological-economicpolitical environment.

Based on practical experience with implementing systemic Foresight activities [15, 31], following main quality criteria for internal validity of futuring activities have been summarised:

- Goal and stakeholder oriented design of the 'futuring' initiative (well-defined scope with focus on the relevant actors and their specific objectives);

- Systemic and participatory approach with broad stakeholder involvement and engagement in the 'futuring' process;

- Integrative approach with appropriate combination of Strategic Intelligence (SI) and sense-making activities and a proper use of SI tools along the policy cycle;

- Action and impact oriented process with focus on implementing the jointly developed 'futuring' results.

The ultimate aim of 'futuring' activities is to shape the future towards an aspired, broadly in the community shared, future scenario [17]. Thus, the impact of the 'futuring' process and results has been described as the main criterion for external validity of such activities. From a practical and impactoriented perspective [1], the more impact a 'futuring' process has achieved in the socio-technological-economic-political environment the more successful it has been. Effective 'futuring' activities substantially contribute to strategic decision-making and constituency building at multiple levels - from macro-level governance of innovation ecosystems, to meso-level value chains and networks, to micro-level innovation actors.

With regard to the criteria for internal validity, the assessment of the ManuFuture vision and constituency building process has shown:

- A reference model which clearly describes the goal of the process (pursuing competitive sustainable manufacturing) and the stakeholder involvement from 'triple helix' innovation actors right from the beginning;

- Broad stakeholder involvement and engagement with e.g. about 50 high-level executives and experts involved in drafting the ManuFuture 2020 Vision and about 3.000 experts involved in the online Delphi survey of the MANVIS project;

- Appropriate combination of SI and sense-making activities in a circular process of SI generation, diffusion, adoption and use along the policy cycle with specific Foresight, roadmapping, implementation and monitoring phases;

- An action and impact oriented approach with focus on implementing the jointly developed results e.g. supported by the $7^{\text {th }}$ EU Framework Programme for Research as well as national and regional programs.
With regard to impact as the main criterion for external validity, the assessment of the ManuFuture's vision 2020 and the subsequent strategic research agenda and roadmaps has shown impact on multiple innovation actors from various sectors at multiple levels. Along the ManuFuture Road, e.g. the European Factories-of-the-Future research program has been established, the German Industry 4.0 idea has been inspired and related strategy processes in manufacturing companies as well as in their business environment have been initiated. In conclusion, the ManuFuture Road represents an ideal systemic multi-actor, multi-sector and multi-level approach:

- Multi-actor: stakeholders from public authorities and financial institutions, to industry, universities and research organisations have been involved and affected;

- Multi-sector: 23 industrial sectors and various political "sectors" along the knowledge triangle education - research - innovation have been addressed;

- Multi-level: supported and coordinated European, national and regional programmes and initiatives, contributed to the European manufacturing-related research and innovation area and the related national/regional innovation systems.

The ManuFuture Vision 2020 generation and implementation process sets the frame and depicts the ambition as well as the challenge for the upcoming vision building process with the time horizon of 2030 and beyond [38]. ${ }^{14}$ This upcoming scenario and vision building process with the aim to create a new vision 2030 for a smart, clean and human-centered EU industry should be adaptive to the various stakeholders' needs and objectives like the ManuFuture 2020 process in the past. Furthermore, the vision 2030 process has to be at least so effective, considering the more and more complex, knowledgebased, dynamic and globalizing innovation landscape. New paradigms such as Open Innovation 2.0 [8], which refers to the shared value creation process in the quadruple or quintuple helix innovation model, the digitising industry [12] and the circular economy [9] are currently discussed as important drivers for radical changes in the European Research and Innovation Area.

The increasing digitisation (Industry 4.0) of the whole economy will lead to more intelligent (in terms of more IT-based) and more networked manufacturing in new emerging production ecosystems, breaking up traditional value chains. The same is true for the circular economy approach, which is pushed forward by policy makers and pioneer companies in the view of pressing challenges such as climate change, increasing pollution and shortening of ecological resources as well as by the younger

\footnotetext{
${ }^{14}$ The European Commission supports the 2030 scenario and vision building process with the FUTURING project that is funded under the European Union's Horizon 2020 research and innovation programme (grant agreement No 723633).
} 
generation with changing consumption patterns more conducive to sharing instead of possessing products.

Thus, the ecosystem approach has to be in the centre of the upcoming vision and constituency building process, integrating all relevant relations of the quintuple helix model, and broadening the scope with manufacturing as key enabling function in a highly networked, digitizing and circular economy of the future. It is imperative to take into account all relevant stakeholders in a systemic approach, affecting the whole ecosystem of added-value manufacturing, and therefore contributing to sustainable growth and social welfare in Europe and beyond.

Open Access This article is distributed under the terms of the Creative Commons Attribution 4.0 International License (http:// creativecommons.org/licenses/by/4.0/), which permits unrestricted use, distribution, and reproduction in any medium, provided you give appropriate credit to the original author(s) and the source, provide a link to the Creative Commons license, and indicate if changes were made.

\section{References}

1. Amanatidou E, Guy K (2008) Interpreting foresight process impacts: steps towards the development of a framework conceptualising the dynamics of 'foresight systems. Technol Forecast Soc Chang 75(4):539-557

2. Armbruster H, Dreher C Jung-Erceg P (2008) European Manufacturing Visions ManVis 2020. The European Foresight Monitoring Network, EFMN Brief No. 53. http://www.foresight-platform. eu/wpcontent/uploads/2011/04/EFMN-Brief-No.-53-EuropeanManufacturing-Visions-ManVis-2020.pdf. Accessed 5 July 2016

3. Carayannis E, Campbell D (2010) Triple helix, quadruple helix and quintuple helix and how do knowledge, innovation and the environment relate to each other? a proposed framework for a transdisciplinary analysis of sustainable development and social ecology. Int J Social Ecol Sustain Dev 1:41-69

4. Carayannis E, Campbell D (2011) Open innovation diplomacy and a 21 st Century Fractal Research, Education and Innovation (FREIE) Ecosystem: building on the quadruple and quintuple helix innovation concepts and the "Mode 3 " knowledge production system. J Knowl Econ 2(3):327-372

5. Carayannis E, Campbell D, Barth T D (2012) The quintuple helix innovation model: global warming as a challenge and driver for innovation. J Innov Entrepreneurship 1. doi: 10.1186/2192-5372$1-2$

6. Clar G, Sautter B (2014) Thinking \& shaping futures with actors of the "Spitzencluster" MicroTEC Südwest. a participatory approach to improving policy impact. In: Decker $M$ et al (eds) Technikfolgenabschätzung im politischen System. Zwischen Konfliktbewältigung und Technologiegestaltung. edition sigma, Berlin, pp 163-170

7. Cornish E (2004) Futuring: the exploration of the future. World Future Society, Bethesda

8. Curley M, Salmelin B (2013) Open innovation 2.0: a new paradigm, white paper released after the Open Innovation 2.0 Conference in Dublin, Ireland. file://C:/Users/user/Downloads/ OISPGOpenInnovation20ANewParadigm-WhitePaper.pdf. Accessed 15 August 2016

9. Ellen MacArthur Foundation, Stiftungsfonds für Umweltökonomie und Nachhaltigkeit, McKinsey Center for Business and
Environment (2015) Growth Within: A Circular Economy Vision for a Competitive Europe. https://sunstiftungsfonds.files. wordpress.com/2015/06/growth_within_for_print1.pdf Accessed 15 August 2016

10. Etzkowitz H, Leydesdorff L (2000) The dynamics of innovation: from National Systems and "Mode 2" to a Triple Helix of universityindustry-government relations. Res Policy 29(2):109-123

11. European Commission (2004) ManuFuture - a vision for 2020: assuring the future of manufacturing in Europe. Office for Official Publications of the European Communities, Luxembourg

12. European Commission (2016) Digitising European Industry reaping the full benefits of a digital single market. SWD 110 final. European Commission, Brussels

13. European Forum on Forward Looking Activities - EFFLA (2013) Towards standards in Forward Looking Activities for the EC. Policy Brief No. 14. https://ec.europa.eu/research/innovationunion/pdf/expert-groups/effla-reports/effla_pb_14_-_towards_a foresight_standard.pdf. Accessed 15 August 2016

14. Gassmann O, Enkel E, Chesbrough H (2010) The future of open innovation. R\&D Manag 40(3):213-221

15. Gerhold L, Holtmannspötter G, Neuhaus C, Schüll E, SchulzMontag B, Steinmüller K (2015) Standards und Gütekriterien der Zukunftsforschung: Ein Handbuch für Wissenschaft und Praxis. Springer, Wiesbaden

16. Geyer A, Scapolo F, Boden M, Döry T, Ducatel K (2003) The future of manufacturing in Europe 2015-2020: The Challenge for Sustainability. IPTS Technical Report Series, EUR 20706 EN

17. Godet M (2001) Creating futures: scenario planning as a strategic management tool. Brookings Institution Press, Washington

18. Hamel G, Prahalad CK (1994) Competing for the future. Harvard Business School Press, Boston

19. Johann D, Marinelli E (2012) Delphi-based Foresight for a Strategic Research Agenda on the Future of European Manufacturing: Follow-up of "ManVis". The European Foresight Plattform, EFP Brief No. 247. http://www.foresight-platform.eu/wpcontent/uploads/2013/01/EPF-Brief-No.-247 ManVis Follow-up. pdf. Accessed 15 August 2016

20. Jovane F (2007) Towards knowledge and innovation communities. Presentation at the ManuFuture Conference 2007, 4 December 2007, Porto, Portugal. http://manufuture2007.inescporto. pt/documents/morning-day-2/manufuture2007-jovane.pdf. Accessed 10 August 2016

21. Jovane F (2009) Leadership of European manufacturing industry. In: Jovane F, Westkämper E, Williams D (eds) The ManuFuture road: towards competitive and sustainable high-adding-value manufacturing. Springer, Berlin, pp 5-29

22. Jovane F, Yoshikawa H, Alting L, Boër CR, Westkämper E, Williams D, Tseng M, Seliger G, Paci AM (2008) The incoming global technological and industrial revolution towards competitive sustainable manufacturing. CIRP Ann Manuf Technol 57(2):641659

23. Jovane F, Westkämper E, Williams D (2009) The ManuFuture road: towards competitive and sustainable high-adding-value manufacturing. Springer, Berlin

24. Jovane F, Westkämper E (2009) The European strategic initiative ManuFuture. In: Jovane F, Westkämper E, Williams D (eds) The ManuFuture road: towards competitive and sustainable highadding-value manufacturing. Springer, Berlin, pp 53-87

25. Kuusi O, Cuhls K, Steinmüller K (2015) Quality criteria for scientific futures research. Futura 34(1):60-77

26. Kuusi O, Cuhls K, Steinmüller K (2015) The futures map and its quality criteria. Eur J Futures Res 3:22. doi:10.1007/s40309-0150074-9

27. ManuFuture High Level Group and Support Group (2006) Strategic Research Agenda: Assuring the future of manufacturing in Europe. 
Report of the ManuFuture Platform. http://www.manufuture. org/manufacturing/?page id=10. Accessed 5 October 2016

28. Molina A (1995) Sociotechnical constituencies as processes of alignment: the rise of a large-scale european information technology initiative. Technol Soc 17(4):385-412

29. Rohrbeck R, Hölzle K, Gemünden HG (2009) Opening up for competitive advantage - how Deutsche Telekom creates an open innovation ecosystem. R\&D Manag 39(4):420-430

30. Sautter B, Clar G (in press) Strategic guidance in leading-edge clusters for sustainable business success in future markets. Int $\mathrm{J}$ Business Syst Res

31. Sautter B, Hafner-Zimmermann S (2015) Quality criteria for systemic foresight activities: Tackling grand societal challenges and individual investment decisions. Presentation at the World Conference Futures Research, 11-12 June 2015, Turku, Finland. https://futuresconference2015.files.wordpress.com/2015/06 /bjoern sautter.pdf. Accessed 11 July 2016
32. Shala $\mathrm{O}$ (2015) A new path in foresight validation? discussing the socio-epistemic underpinning of foresight quality criteria. Eur J Futures Res 3:19. doi:10.1007/s40309-015-0079-4

33. Smits R, Kuhlmann S (2004) The rise of systemic instruments in innovation policy. Int J Foresight Innov Policy 1:4-32

34. Tübke A, Ducatel K, Gavigan J, Moncada-Paterno-Castello P (2001) Strategic policy intelligence: Current trends, the state of play and perspectives. IPTS Technical Report Series, EUR 20137 EN

35. Tversky A, Kahneman D (1981) The framing of decisions and the psychology of choice. Science 211(4481):453-458

36. Vasamo AL (2015) The Radical Technology Inquirer (RTI) tool for technology anticipation and evaluation: introduction and quality criteria analysis. Eur J Futures Res 3:18. doi:10.1007/s40309-015-0081-x

37. Westkämper E (2009) The proactive initiative ManuFuture roadmap. In: Jovane F, Westkämper E, Williams D (eds) The ManuFuture road: towards competitive and sustainable highadding-value manufacturing. Springer, Berlin, pp 123-147

38. Westkämper E (2014) Towards the re-industrialization of Europe: a concept for manufacturing for 2030. Springer, Berlin 